\title{
Intermediary Spaces Linking Urban Space to Buildings: Functions and User Satisfaction in Three Mixed-Use Complexes
}

\author{
You-Mi Lee ${ }^{1}$, Suk-Kyung Kim² ${ }^{2}$ Ha-Ni Moon ${ }^{3}$ \\ ${ }^{1}$ Department of Housing and Consumer Studies, Sangmyung University, Seoul, Korea \\ ${ }^{2}$ School of Planning, Design, \& Construction, Michigan State University, East Lansing, Michigan, USA \\ ${ }^{3}$ Architectural Environment Design Institute Borie, Seoul, Korea \\ Correspondence: Suk-Kyung Kim, School of Planning, Design, \& Construction, Michigan State University, 201 \\ B Human Ecology Building, East Lansing, MI 48842, USA. Tel: 1-517-353-9367. E-mail: kimsk@msu.edu
}

Received: June 17, 2013 Accepted: July 8, 2013 Online Published: August 5, 2013

doi:10.5539/jsd.v6n9p12 URL: http://dx.doi.org/10.5539/jsd.v6n9p12

This study was supported by a 2013 Research Grant from Sangmyung University in Seoul, Korea

\begin{abstract}
Contemporary cities have different types of mixed-use complexes to increase urban density for preventing suburban sprawl. Intermediary space is a third space that connects a mixed-use complex and its surrounding area This study examined the main functions of intermediary spaces and user satisfaction with the intermediary spaces' amenities in three European mixed-use mega-complexes. It focused on various amenity elements in intermediary spaces, including daylight, noise, green space, condition of facility, management, and accessibility. The data were collected through site visits and a questionnaire survey of space users in the three mixed-use complexes. Major findings identified the main purposes of visitation to intermediary spaces, the amenity elements affecting user satisfaction, and the relationship between users' satisfaction with these spaces and their perceptions of the complexes. Results showed that intermediary spaces functioned in various ways and users' satisfaction with these spaces related closely to their perceptions of complex buildings. Evidence from the research will provide important guidelines for improving environmental quality of intermediary spaces to make them more functional for space users.
\end{abstract}

Keywords: mixed-use complex, intermediary space, amenity, user satisfaction, green space

\section{Introduction}

\subsection{Background}

Mixed-use development has become an important principle in contemporary discussions of urbanscapes and urban design paradigms, such as sustainable development, New Urbanism, and Compact City (Grant, 2002; Hirt, 2007). In Korea, where compact development is the prevalent urban pattern that aims to prevent suburban sprawls, numerous mixed-use mega-complexes are constructed every year in order to use land efficiently. It is thus easy to find different types of mixed-use complexes in Korean cities.

All such complexes include intermediary spaces that connect outdoor spaces with indoor complexes. Despite the significant increase in mixed-use developments, research on mixed-use complexes in Korea has been insufficient. Prior studies on mixed-use complexes provide little information about intermediary spaces.

Intermediary space is defined as a "third" space that connects two different spaces, such as a mixed-use complex and its surrounding area (Merriam-Webster Online Dictionary, 2009). Intermediary spaces physically connect mixed-use complexes and their surrounding areas. These types of areas are critical in mixed-use complexes because they offer physical integration of the complexes' segregated functions within the urban space (Kisho, 1979; Strauven, 1998). They fill out the spatial gap between a mixed-use complex and its surrounding area (Broadbent, 1990; Lee, Moon, \& Lee, 2008). Additionally, intermediary spaces may serve other purposes, such as traffic, resting, and casual meetings. These varied functions enable assorted occupants to use intermediary spaces of mixed-use complexes. Intermediary spaces are, therefore, expected to offer comfortable and satisfactory environments for the space users with the aim of meeting their diverse visit purposes and enhancing 
the vitality of nearby mixed-use complexes. Well-designed intermediary spaces may positively affect users' satisfaction with the mixed-used complexes where those spaces are located.

Despite a significant increase in mixed-use developments and the important roles of intermediary spaces in mixed-use complexes, empirical analysis-based design guidelines for mixed-use complexes and intermediary spaces are rarely available.

In fact, many intermediary spaces in recent Korean mixed-use mega-complexes have neither been carefully designed to meet users' demands and needs nor improved the urban landscape (Lee \& Yoo, 2010; Yang \& Lee, 2012). No code-based guideline exists for creating or managing these spaces, although many mixed-use complexes are being constructed in Korea (Shin, Kim, Jeon, \& Choi, 2009). Consequently, the intermediary spaces in many mixed-use complexes fail to connect the traffic from their locations to other destinations, such as adjacent buildings or transit. The physical environments of the intermediary spaces do not offer a pleasant user experience due to high noise levels, unorganized space layouts, and no thorough analysis of spatial functions or ambiance. The spaces are often problematic because they lack design and maintenance guidelines, which negatively affects urban environments and produces unpleasant experiences for users who usually occupy these spaces in transit to the main complex or another destination.

Nonetheless, efforts to improve functions of intermediary space designs and turn them into pleasant and efficient transitional spaces have been insufficient. Only a few studies have explored mixed-use complexes in Korea and provided little information about intermediary spaces in mixed-use complexes. Because the number of newly constructed mixed-use buildings increases rapidly, it is essential to investigate empirically the general functions of intermediary spaces, solicit user opinions of these spaces to improve physical environment quality, and discuss future directions for designing new spaces and managing existing ones.

To establish future design and managerial guidelines, it is necessary to look at exemplary cases of mixed-use complexes and examine diverse functions of the intermediary spaces and their effects on user opinions of each type of complex (Kim \& Yang, 1997; Moon, Chang, \& Lee, 2011; Yang \& Lee, 2012). To achieve the goals of this study, intermediary space in recent European mixed-use complexes should be considered because that area's urban design approaches and high levels of mixing (Beatley, 2000; Marion \& Lloyd-Jones, 1997) can provide diverse options for designers in other cultures. Past studies relevant to this topic (Jung, Lee, \& Han, 2009; Lee, Moon, \& Lee, 2008) also emphasized the need to examine mixed-use complexes in Europe, where many examples can be found to suggest designs that could improve the quality of intermediary spaces.

\subsection{Purpose and Scope of Study}

The purpose of this study was to investigate environmental characteristics and roles of intermediary spaces in mixed-use complexes. We examined user satisfaction and opinions to determine explanatory variables affecting user satisfaction with the amenity of intermediary spaces. The ultimate goal was to provide design considerations for the intermediary spaces of mixed-use complexes based on discussion of improvements in the current intermediary space settings. The upgraded intermediary environments, founded on the analysis of diverse functions and user opinions, are expected to improve the overall quality of mixed-use complex environments and their urban surroundings.

This study targeted three European complexes representing the different mixed-use complex types most commonly emulated in Korea: (1) a mixed-use complex occupied mainly by office spaces (called an office complex), (2) a mixed-use complex having mainly commercial and retail spaces (called a commercial complex), and (3) a mixed-use complex offering many entertainment opportunities (called an entertainment complex). Commonalities and differences among the three types were found in terms of functions, environmental elements, and user satisfaction.

Although the targets of this study were geographically different from those in Korea, we expected the research results to provide valuable information that could be applied in different geographic locations because urban functions and densities of Korean cities resemble those of many European cities. This empirical research conducted with European cases was also expected to provide a foundation for discussing user experience in intermediary spaces and improving the quality of mixed-use complexes in other geographical locations. The findings which focused on user satisfaction with intermediary spaces of European mixed-use complexes should contribute to the design of future intermediary space environments. 


\section{Literature Review}

\subsection{Mixed-Use Complex and Intermediary Space}

Mixed use means multiple land use by including two or more types of different buildings or developments (Hirt, 2007; Lau, Giridhara, \& Ganesan, 2003). A mixed-use project is generally classified as any composition of more than three revenue-producing functions: office, retail, and residential uses (Kim \& Kim, 2009; Schwanke, 2003; Witherspoon, 1976). In this article, mixed-use complex is defined as a complex that is physically and functionally integrated with three or more functions located within it.

As mentioned, intermediary spaces are third or transitional spaces that connect two different areas. They are semipublic spaces that link a mixed-use complex with urban public spaces. In this study, intermediary space was limited to outdoor spaces that connected a mixed-use complex with an urban space or adjacent structure.

\subsection{Previous Studies in Mixed-Use Complexes and Intermediary Spaces}

Mixed-use complexes have been built all over the world. Many studies exploring them have been conducted in Japan (Lee, Moon, \& Lee, 2008; Lee, Park, \& Ha, 2008) and Hong Kong (Lau, Giridharan, \& Ganesan, 2005; Zhang, 2000), while only a few have been done in Korea (Jung, Lee, \& Han, 2009; Lee \& Kim, 2006). Other research studies on mixed-use complexes have been completed in the Netherlands (Hoppenbrouwer \& Louw, 2005).

Previous studies on mixed-use complexes focused on different classifications and planning characteristics of complexes. They classified them by location (Kim \& Kim, 2009), main functions (Kim \& Kim, 2009; Lee \& Lee, 2004; Han, Park, \& Lee, 2009), owners (Coupland, 1996), and planning characteristics (Lee, 1998). They listed the planning characteristics as: interior space planning (Choi, 2008; Lee, Park, \& Ha, 2008), locations by use (Hirt, 2007; Lau, Giridharan, \& Ganesan, 2005), legislation (Shin, Kim, Jeon, \& Choi, 2009), and circulation (Shin \& Kim, 2002). Only a few studies explored intermediary spaces in mixed-use developments. Some articles about amenity or accessibility in mixed-use complexes looked at Japanese and European outdoor spaces without considering intermediary spaces (Shin \& Kim, 2005; Lee, Park, \& Ha, 2008). Yet there are a few studies that focused on the pedestrian passages of intermediary spaces in Japanese mixed-use complexes (Lee, Moon, \& Lee, 2008) and intermediary spaces in office buildings but not mixed-use complexes (Jang \& Lee, 2006).

Still, most studies of European complexes have concentrated on planning and development characteristics (Choi, 2008; Hoppenbrouwer \& Louw, 2005) rather than on detailed amenity-related elements in those spaces. In terms of Korean mixed-use complexes and intermediary spaces, only one article about amenity in intermediary space was found, but it focused more on amenity in mixed-use complexes than in intermediary spaces (Jung, Lee, \& Han, 2009).

\subsection{Amenity in Intermediary Spaces of Mixed-Use Complexes}

Amenity generally means "the quality of being pleasant or agreeable" (Merriam-Webster Online Dictionary, 2009). Amenity in the urban and architectural field entails having characteristics that make a property attractive and convenient (Oxford Advanced Learner's Dictionary, 2009) in terms of any beneficial qualities or environmental characteristics created by architectural designers (Allison, 1991). The major design elements related to amenity in previous studies were daylight, noise (Lee et al., 2002), amount of green space and location of rest space (Shin \& Kim, 2002), facility (Lee, Park, \& Ha, 2008), and accessibility (Shin \& Kim, 2002).

The current research defined amenity as any positive environmental quality that makes the intermediary space in a mixed-use complex pleasant and comfortable for users. This study focused on detailed elements of amenity, including daylight, noise, green space, condition, management (i.e., cleanliness), and accessibility (especially by public transportation). The investigation examined user satisfaction with the design elements and overall amenity in intermediary spaces.

\section{Methodology}

\subsection{Data Collection and Instrument}

An empirical study was designed utilizing site visits and administering questionnaire surveys to on-site visitors in three European mixed-use complexes. Subject complexes for the survey were selected based on four guidelines. First, as a mixed-use complex is generally defined, the target complexes should integrate three or more functions. Second, the complexes should have been completed after the year of 1990, when mixed-use complexes were actively constructed in Europe and their design thus contributed to contemporary mixed-use complex design (Beatley, 2000; Helen, 1997). Third, each selected case needed to represent major mixed-use complexes identified in previous studies (Lee, 1998; Lee \& Lee, 2004): office complex, commercial complex, 
and entertainment complex. Four, in view of the complex's spatial characteristics, the surrounding areas should have been revitalized accordingly, more than two modes of public transportation should be connected to the complex, and the complex should have activated intermediary outdoor space.

Based on these guidelines, three types of complexes were selected: One Canada Square (as an office complex), Euralille (as a commercial complex), and Sony Center (as an entertainment complex). Earlier studies supported the suitability of these facilities as representative of mixed-use complexes (Choi, 2008; Kim et al., 2008; Oh, 2006).

Target places in these mixed-use complexes were intermediary spaces located between urban space and the mixed-use complexes. Each intermediary space surveyed was chosen based on five conditions: (a) It had public transportation nearby connecting the complex to the urban center, (b) it was located near the main pedestrian circulation that linked the complex with urban space, (c) it was adjacent to the main plaza, (d) it was an appropriate space for questionnaire surveys due to easy contact with many space users, and (e) it was suitable for evaluating natural light, noise, facilities, pedestrian circulation, and access to transportation.

\subsection{Questionnaire and Analysis Design}

A questionnaire survey administered to on-site visitors considered geographical and physical characteristics of the subject sites. The questionnaire consisted of three parts: (a) respondent characteristics, including demographic information, (b) purpose of visit to the intermediary spaces for determining the functions of these spaces, and (c) opinions about the amenity of the subject intermediary spaces. Questions about satisfaction level of six amenity elements in intermediary spaces were measured on a 5-point Likert-type scale ranging from $1=$ not at all satisfied to $5=$ very satisfied. The elements were noise, daylight, green space, management, facility condition, and accessibility to the space. The questionnaire was tested through a pilot study to examine if the questions and data collection procedure were reliable and valid to be implemented in this type of an on-site survey with convenient samples.

The actual survey was conducted in October 2008. On-site surveyors contacted users in each intermediary space. A total of 121 respondents participated voluntarily after learning about the research purpose in a brief introduction, thus generating about a $75 \%$ participation rate. Several respondents were interviewed casually, allowing researchers to ask additional questions about their responses, if necessary.

Descriptive statistics and mean difference tests were used to examine demographic characteristics. Linear regression models were applied to predict satisfaction with intermediary spaces. Spearman correlation coefficients verified the relationships between satisfaction with intermediary space and satisfaction with the mixed-use complex where the intermediary space was located.

Although the data were collected rigorously based on voluntary participation, the research still has several limitations. (1) Due to the tight budget and time limit, the study could not employ random sampling methods. The sample size per mixed-use complex type was insufficient for elaborate statistical analysis. Still, the samples were selected considering the mixed-use complex types and several demographical subsets, including gender. The sampling method used, therefore, can be referred to as the quota sampling method (Trochim, 2006). (2) Because of the small sample size, user satisfaction with amenities in intermediary spaces was examined by combining three cases. (3) Lastly, the questionnaire was administered in three mixed-use complexes only one time during the same season. Therefore, continuous or repetitive visitations by users to the subject spaces or their opinions during different weather or outdoor conditions were not explored.

\section{Findings and Discussion}

\subsection{General Characteristics of Target Intermediary Spaces}

General characteristics of the three complexes were identified during the site visits (see Table 1 and Figure 1). One Canada Square was an office complex located in Canary Wharf, $8 \mathrm{~km}$ from London, England. The survey target space was a plaza in front of the complex where metro users passed through to go to One Canada Square. We observed many users during the site visits. We also found that facilities (such as benches and waste baskets), management, accessibility to public transportation, and pedestrian roads were in very good condition (Table 2). 
Table 1. Target complex characteristics

\begin{tabular}{llll}
\hline Division & One Canada Square & Euralille & Sony Center \\
\hline Type & Office complex & Commercial complex & Entertainment complex \\
Year of completion & 2005 & 1995 & 2000 \\
Gross floor area & $115,000 \mathrm{~m}^{2}$ & $127,500 \mathrm{~m}^{2}$ & $132,500 \mathrm{~m}^{2}$ \\
Uses & $\begin{array}{l}\text { Office (finance), commerce, } \\
\text { exhibition, etc. }\end{array}$ & Commerce, office, & Theater, office, commerce, \\
& & & hotel, residence, etc. \\
\hline
\end{tabular}

Euralille (see Table 1 and Figure 1), a commercial complex located in Lille, France, is connected to Gare Lille Europe (a European high-speed train station) and Gare Lille Flandres (a French regional station). The survey target space was an open square between Euralille and Gare Lille Europe. Noise was controlled very well there through the height difference between the open square and the driveways, except for music performances during weekends. In addition, location of nearby parks, daylight, and management were in very good condition based on the site observation (see Table 2). The shopping mall and a huge grocery store in the complex allowed easy access to this space.

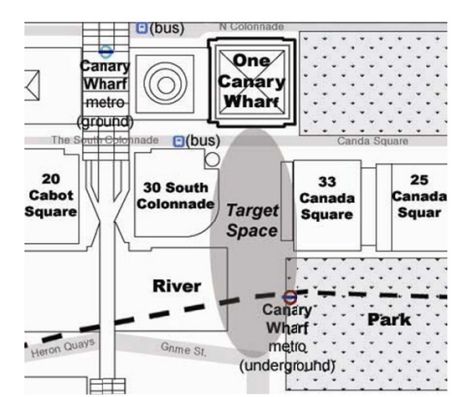

One Canada Square



Eura lille



Sony Center

Figure 1. Site plan of target complexes (no scale)

Table 2. Observed characteristics of target intermediary spaces

\begin{tabular}{|c|c|c|c|}
\hline Division & $\begin{array}{l}\text { One Canada Square Office } \\
\text { Complex }\end{array}$ & $\begin{array}{l}\text { Euralille Commercial } \\
\text { Complex }\end{array}$ & $\begin{array}{l}\text { Sony Center Entertainment } \\
\text { Complex }\end{array}$ \\
\hline Target space location & Front plaza & Front plaza & Entrance plaza \\
\hline Noise control & $\begin{array}{l}\text { Good } \\
\text { (Due to distance between plaza } \\
\text { \& driveway) }\end{array}$ & $\begin{array}{l}\text { Very good } \\
\text { (Due tolevel differences } \\
\text { between plaza \& driveway) }\end{array}$ & $\begin{array}{l}\text { Good } \\
\text { (Due to complex building } \\
\text { surrounding plaza) }\end{array}$ \\
\hline Green space elements & Trees, flowerbeds & Big trees, flowerbeds & Trees, flowerbeds, fountains \\
\hline Nearby park location & Visible \& adjacent & Visible \& adjacent & Invisible $\&$ adjacent \\
\hline Daylight condition & $\begin{array}{l}\text { Modest } \\
\text { (Shadow falls from nearby } \\
\text { buildings for a time) }\end{array}$ & $\begin{array}{l}\text { Very good } \\
\text { (Less shade from nearby } \\
\text { buildings) }\end{array}$ & $\begin{array}{l}\text { Modest } \\
\text { (Some parts of spaces under } \\
\text { shade from surrounding } \\
\text { buildings \& tented roof) }\end{array}$ \\
\hline Number of facilities & Enough & $\begin{array}{l}\text { Not enough compared } \\
\text { to overall area }\end{array}$ & Enough \\
\hline Management & Very good & Very good & Very good \\
\hline Accessibility from transit & $\begin{array}{l}\text { Very good } \\
\text { (Connected to metro by } \\
\text { escalator) }\end{array}$ & $\begin{array}{l}\text { Very good } \\
\text { (Connected to building } \\
\text { containing train \& metro) }\end{array}$ & $\begin{array}{l}\text { Very good } \\
\text { (Directly connected with metro } \\
\text { by escalator \& bus stop) }\end{array}$ \\
\hline $\begin{array}{l}\text { Driveway \& pedestrian } \\
\text { road }\end{array}$ & $\begin{array}{l}\text { Separated from driveway on } \\
\text { same level; separated from metrc }\end{array}$ & $\begin{array}{l}\text { Separated from driveway in } \\
\text { three dimensions }\end{array}$ & $\begin{array}{l}\text { Separated from driveway on } \\
\text { same level }\end{array}$ \\
\hline
\end{tabular}


Sony Center in Figure 1 is an entertainment complex located in Berlin, Germany, and includes a 3D film theater, film center, and hotel. Big events such as film festivals take place in this building periodically.

The target space for the survey was an entrance plaza used by metro passengers who visit this center. A part of the target space bordering the driveways was a little noisy, but that did not seem to bother users. Management, access to public transportation, and pedestrian roads were all in very good condition based on the site observation (see Table 2).

\subsection{Questionnaire Survey Results}

\subsubsection{Demographic Characteristics of Survey Respondents}

Respondent demographic characteristics included age, gender, and main activity area (workplace and residential). Based on the purposive sampling method (i.e., quota sampling), we had similar numbers of male and female respondents, even though a slightly greater number of females completed the surveys at Euralille and Sony Center $(62.5 \%, 53.7 \%)$. The proportion of respondents in their teens or 20 s was higher compared to those in their $30 \mathrm{~s}(60.0 \%, 70.0 \%, 53.7 \%)$, while age distributions were similar across all three groups.

To figure out whether respondents were familiar with the target intermediary spaces and mixed-use complexes, the investigators determined whether respondents' workplaces and residential areas were near the target space. There were more respondents whose offices and residences were located near the target space in the office complex (One Canada Square) than in the commercial complex (Euralille) or the entertainment complex (Sony Center). We included several questions about the site to look into the main reason for this difference. Of those who replied that their workplace and residential areas were near the target space, $43 \%$ worked around the office complex. These results seemed to be related to the frequency and purpose of visiting target complexes and intermediary spaces, which will be discussed later in this paper.

\subsubsection{Space Utilization}

\subsubsection{Frequency and Purpose of Visiting the Complexes}

The frequencies and purposes of visiting the complexes were examined to understand the functions for the intermediary spaces. Table 3 also shows the results with visitors' transportation modes.

Table 3. Purpose and frequency of visiting complexes

\begin{tabular}{llcccc}
\hline Division & & $\begin{array}{c}\text { Office Complex } \\
(n=40)\end{array}$ & $\begin{array}{c}\text { Commercial } \\
\text { Complex } \\
(n=40)\end{array}$ & $\begin{array}{c}\text { Entertainment } \\
\text { Complex } \\
(n=41)\end{array}$ & $\begin{array}{c}\text { All } \\
(n=121)\end{array}$ \\
\hline Frequency & First visit & $7(17.5)$ & $12(30)$ & $8(19.5)$ & $27(22.3)$ \\
& Once a week & $15(37.5)$ & $13(32.5)$ & $3(7.3)$ & $31(25.6)$ \\
& Once a month & $7(17.5)$ & $4(10)$ & $13(31.7)$ & $24(19.8)$ \\
& Four times a year & $7(17.5)$ & $5(12.5)$ & $5(12.2)$ & $17(14.0)$ \\
Purpose & Other & $4(10)$ & $6(15)$ & $12(29.3)$ & $22(18.2)$ \\
& Shopping & $10(25)$ & $15(37.5)$ & $9(22)$ & $34(28.1)$ \\
& Watching movies & $3(7.5)$ & $1(2.5)$ & $17(41.5)$ & $21(17.4)$ \\
& Dining & $6(15)$ & $5(12.5)$ & $1(2.4)$ & $12(9.9)$ \\
& Use transportation & $1(2.5)$ & $8(20)$ & $5(12.2)$ & $14(11.6)$ \\
Transportation & Metro/train & $6(15)$ & $3(7.5)$ & $3(7.3)$ & $12(9.9)$ \\
mode & Meeting & $14(35)^{*}$ & $8(20)$ & $6(14.6)$ & $28(23.1)$ \\
& Bus & $6(15.8)$ & $7(17.9)$ & $4(9.8)$ & $17(25.0)$ \\
& $*$ Other & $6(15.8)$ & $10(25.6)$ & $9(22.0)$ & $25(36.8)$ \\
\hline
\end{tabular}

*Other includes "business purpose" (11 out of 14 respondents) 
The results revealed that the frequencies and purposes of visiting the intermediary space differed by type of complex. In the office complex, the highest percentage was "visiting more than once a week". In the commercial complex, "first visit" and "once a week" were relatively high. In the entertainment complex, "visiting once a month" or "other" were both high. The diverse functions of each complex might have caused these differences. Most respondents in the office complex came to work more than once a week. The commercial complex (Euralille) included a shopping mall and a huge grocery store, and many respondents visited it to buy something there once a week. Most respondents in the entertainment complex visited the 3D film theater, the IMAX cinema, or the film center in the building.

Because visit purposes in the office complex varied, the "other" category had the highest frequency, as indicated in Table 3 (11 out of 14 respondents visited there for business purposes). Respondents visited the commercial complex primarily to shop, and the entertainment complex to watch movies. These results supported the different functions of the three complexes, associated with the frequencies and the purposes of visiting the complexes.

Regarding transportation to the complexes, most visitors used metro or train: $68.4 \%$ to the office complex, $56.4 \%$ to the commercial complex, and $68.3 \%$ to the entertainment complex (see Table 3 ). Thus, a majority of the respondents used public transportation to access these mixed-use complexes.

\subsubsection{Frequency and Purpose of Visiting Intermediary Spaces}

People usually came to the intermediary spaces when they visited or stayed in the mixed-use complexes where the spaces were located. Table 4 shows the frequencies and purposes of visiting the three intermediary spaces. In the office complex and the commercial complex, visitation frequencies of intermediary spaces were similar to those of the complexes where the intermediary spaces belonged.

In the office complex, "visiting more than once a week" had the highest percentage. In the entertainment complex, "visiting once a month" or "other" were both comparatively high. In the commercial complex, the percentage of "first visit" was higher than for "once a week".

Table 4.Visiting purpose and visiting frequency of three intermediary spaces in complexes

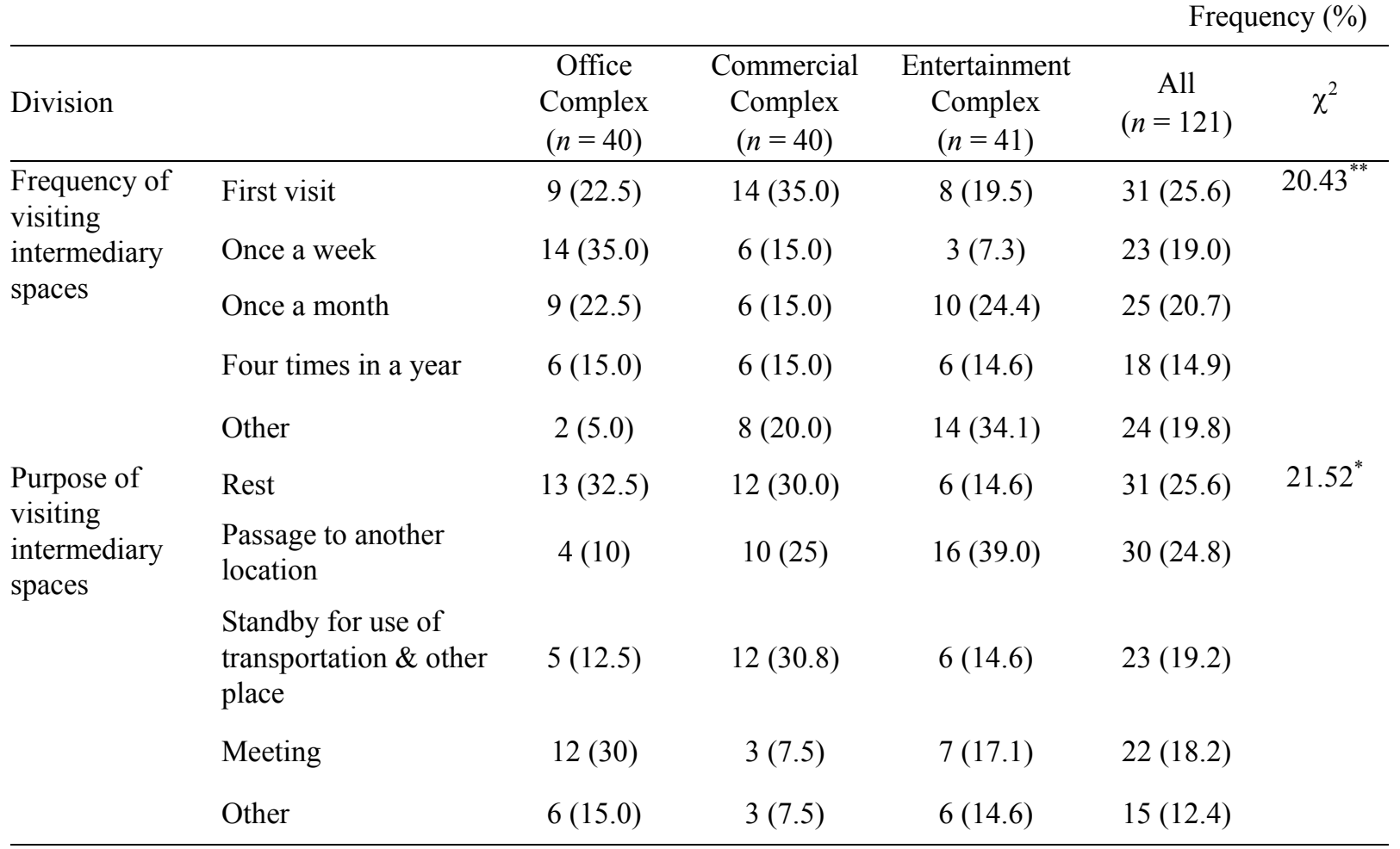

$* p<.05, * * p<.005, * * * p<.001$

Office complex respondents indicated "rest and meeting" as their primary visitation purpose to the intermediary space there. The main reason for visiting the commercial complex was "resting or waiting for transportation to 
visit other places". The major purpose of visiting the intermediary space of the entertainment complex was to transfer to another location (i.e., theaters, offices, hotels). The different purposes for visiting the three intermediary space types might depend on the major functions of the complexes themselves.

Our findings about the purposes of visiting intermediary spaces depended on additional reasons. Most respondents in the office complex were working nearby. The majority thus visited the intermediary space for resting or meeting someone, as this space was near the metro station. Euralille was a commercial complex that included a shopping mall. The European high-speed train was located near this complex. Most respondents thus used the intermediary space to rest, to wait for transportation, or to stay briefly before entering the shopping mall. Many respondents in Sony Center used the intermediary space to transfer to another area because this space was connected to the entrances of both a plaza and a metro station. These results supported additional functions of intermediary spaces rather than just the transitional space function that connects the outside to the inside of a building.

\subsubsection{Satisfaction with Amenity of Intermediary Spaces}

The mean value of all respondents' satisfaction with the amenity in general was higher compared to the neutral point (mean $=3.77$ ), indicating that respondents' views of the intermediary spaces' amenity were positive (Table 5). Comparison of satisfaction scores in terms of amenity of intermediary spaces showed that the mean scores for the office complex $($ mean $=3.90)$ and the commercial one $($ mean $=3.95)$ were higher compared to the entertainment complex (mean $=3.46)$.

The mean values of satisfaction with amenity for the individual physical elements showed that management of the space-keeping it clean and usable (mean $=3.84$ )-was the most satisfactory amenity element. Satisfaction with noise (mean $=3.33$ ) was lower than that for management. Noise, daylight, green space, and management were shown to be significant variables explaining levels of satisfaction with the amenity of the intermediary spaces.

Regarding satisfaction with noise level, the commercial complex had the highest score (mean $=3.70$ ) while the entertainment complex $($ mean $=3.46)$ and the office complex $($ mean $=3.05)$ showed lower scores. Some respondents in the entertainment complex and the office complex indicated their low satisfaction was due to noise from nearby public spaces or people using cell phones while resting or waiting in intermediary spaces. However, because the intermediary space of the commercial complex (Euralille) was located above the nearby driveway (which caused major noise problems) and was shielded from the noise sources, respondents' satisfaction with noise was thus higher for this complex compared to that of the other two groups.

The satisfaction score for daylight was highest in the commercial complex (mean $=4.20$ ), which was not surrounded by tall buildings like One Canada Square (mean $=3.15)$ nor did it have a tented-roof like Sony Center (mean $=3.15$ ). Based on these results, we inferred that both the location and the design solution of intermediary spaces could affect satisfaction with daylight.

Table 5. Mean differences in satisfaction with amenity of intermediary spaces

\begin{tabular}{lccccc}
\hline \multicolumn{1}{c}{ Division } & $\begin{array}{c}\text { Office } \\
\text { Complex } \\
(n=40)\end{array}$ & $\begin{array}{c}\text { Commercial } \\
\text { Complex } \\
(n=40)\end{array}$ & $\begin{array}{c}\text { Entertainment } \\
\text { Complex } \\
(n=41)\end{array}$ & $\begin{array}{c}F \\
\text { value }\end{array}$ & Mean Value \\
\hline $\begin{array}{l}\text { Amenity of intermediary space } \\
\text { (as a whole) }\end{array}$ & 3.90 & 3.95 & 3.46 & $3.75^{*}$ & 3.77 \\
$\quad$ Noise & 3.05 & 3.70 & 3.24 & $3.42^{*}$ & 3.33 \\
Daylight & 3.15 & 4.20 & 3.15 & $10.75^{* * *}$ & 3.50 \\
Green space & 3.33 & 3.85 & 3.00 & $5.78^{* *}$ & 3.39 \\
Management & 3.48 & 3.90 & 4.15 & $4.27^{*}$ & 3.84 \\
Facility condition & 3.40 & 3.30 & 3.46 & 0.25 & 3.39 \\
Accessibility & 3.65 & 3.98 & 3.95 & 1.01 & 3.86 \\
\hline
\end{tabular}

Note: Scale runs from $1=$ Not at all satisfied to $5=$ Very satisfied.

${ }^{*} p<.05,{ }^{* *} p<.005,{ }^{* * *} p<.001$

Satisfaction with green space was lowest for the intermediary spaces in the entertainment complex (mean = 3.00). Most respondents were dissatisfied because of the lack of green space area and the low number of trees. 
Beyond that, not being able to see the nearby park at this complex could have been another factor inviting these negative opinions. In contrast, the intermediary space in the commercial complex offered a good view of parks and trees and thus a higher satisfaction level (mean $=3.85$ ). In addition to amenity, we also investigated satisfaction with accessibility to the intermediary spaces. The results showed that respondents' satisfaction with the three intermediary space types in the complexes did not significantly differ from one complex to another.

The results showed that respondents' satisfaction varied depending on the elements of the intermediary spaces, although neither the architectural designers nor the facility managers had seriously considered them.

\subsection{Other Explanatory Variables of Satisfaction in Intermediary Spaces}

\subsubsection{Amenity Elements}

This study sought to establish elements that were more influential in users' overall satisfaction with the intermediary space. Multiple regression analyses were utilized to explain the relationship between overall satisfaction with intermediary spaces and the six amenity elements: noise, daylight, green space, facility condition, management, and accessibility.

We employed multiple regression analyses using the stepwise method (see Table 6). Satisfaction with green space $(\beta=.399)$ remained the only predictor in the first stage of the regression model. After adding the second regression block, which included satisfaction with facility condition $(\beta=.199)$, a change in $R$-squared indicated that these variables jointly added some explanatory power. Thus, satisfaction with green space and satisfaction with the condition of the facility appeared to explain satisfaction with intermediary space reliably.

Table 6. Multiple regression analyses predicting satisfaction with intermediary spaces and with amenity elements (by stepwise method)

\begin{tabular}{lccccc}
\hline $\begin{array}{l}\text { Dependent variable: Satisfaction } \\
\text { with intermediary spaces }\end{array}$ & Independent Variables & $\begin{array}{c}R- \\
\text { squared }\end{array}$ & $\beta$ & $t$ & Sig \\
\hline Model 1 & Satisfaction with green space & .159 & .399 & 4.751 & $.000^{* * *}$ \\
Model 2 & Satisfaction with green space & .194 & .331 & 3.771 & $.000^{* * *}$ \\
& Satisfaction with facility & & .199 & 2.262 & $.026^{* *}$ \\
\hline
\end{tabular}

Note: $\beta=$ Standardized Coefficients Beta.

$* p<.05,{ }^{* *} p<.005, * * * p<.001$

\subsubsection{Demographic Variables Explaining Satisfaction with Intermediary Spaces}

To find other explanatory variables of satisfaction with intermediary spaces, the analysis examined group differences in satisfaction by demographic variables. The independent variables were: respondents' gender, age, and main activity area (i.e., workplace and residential).

Table 7. Residents' characteristics and satisfaction with intermediary spaces

\begin{tabular}{lccc}
\hline Category & Subcategory & Mean value & $F$-value \\
\hline Gender & Female & 3.83 & 1.21 \\
& Male & 4.00 & \\
Age & $10-20$ & 4.01 & $2.78^{*}$ \\
& $30 \&$ older & 3.76 & \\
Activity area (work place \& residential area) is & Yes & 3.96 & 1.68 \\
near target space & No & 3.89 & \\
\hline
\end{tabular}

$* \mathrm{p}<\overline{.05, * * \mathrm{p}<.005, * * * \mathrm{p}<.001}$

The results in Table 7 showed that respondents' gender and main activity area (workplace and residential) were not strong explanatory variables of satisfaction with intermediary spaces, while age was a significant explanatory variable $(F=2.775, p<.05)$. The mean values of satisfaction were significantly higher for individuals in their 
teens and $20 \mathrm{~s}($ mean $=4.01)$ than for those in their 30 s and older $($ mean $=3.76)$. Although we did not identify a clear reason for this difference, we assumed that younger people were more satisfied with the intermediary spaces because mixed-use complexes have generally been designed to provide facilities more attractive to younger age groups or to offer easy transition from urban spaces to intermediary spaces and from intermediary spaces to the complexes.

\subsection{Relation Between Satisfaction with Intermediary Spaces and Complexes}

The relationship between user satisfaction with intermediary spaces and with complexes was examined. The results in Table 8 show a significant correlation between overall satisfaction with intermediary spaces and satisfaction with complexes (Spearman's $r=.588, p<.001$ ). Correlation coefficients between satisfaction with detailed design elements of the intermediary spaces and satisfaction with the complexes indicated that noise had the highest correlation coefficient. Green space, daylight, and facility also showed significant correlation coefficients.

Table 8. Correlation coefficients between satisfaction with detailed design elements of intermediary spaces and satisfaction with complexes

\begin{tabular}{llcc}
\hline Items & & Satisfaction with complexes & Rank \\
\hline Satisfaction with detailed design & Noise & $.406^{* *}$ & 1 \\
elements in intermediary spaces & Green space & $.336^{* *}$ & 2 \\
& Daylight & $.267^{* *}$ & 3 \\
& Facility & $.242^{*}$ & 4 \\
& Management & .100 & 6 \\
& Accessibility & .139 & 5 \\
\hline
\end{tabular}

${ }^{*} p<.05, * * p<.01, * * * p<.001$

\section{Summary and Conclusions}

This study examined user satisfaction with amenity in intermediary spaces. It focused on intermediary spaces, or transitional spaces, that connect urban outdoor environments and three mixed-use complexes: an office complex, a commercial complex, and an entertainment complex. The method involved site visits and a questionnaire survey.

The respondents visited the three complexes primarily because of their functions. However, the major findings of our study showed that users had various reasons for visiting the intermediary spaces, the main ones being: resting, waiting for transportation, or meeting someone - in addition to passing through, which had been expected to be the major role of these spaces. These results verified multiple functions of intermediary spaces. We inferred that the location of intermediary spaces, such as their direct connection to a metro station, could provide diverse visitation purposes. The different reasons for visiting intermediary spaces may depend on the major functions of the complexes. Overall, $39.7 \%$ of respondents visited intermediary spaces "more than once a week" and "once a month". These results showed multiple functions of intermediary spaces and a high visitation frequency.

The analysis of satisfaction with six amenity elements showed that noise, daylight, green space, and management accounted for differences in users' satisfaction with intermediary spaces. Users were most satisfied with an intermediary space that had a lower noise level, more daylight, and more green space. In addition, visual openness to green space and well-maintained spaces were considered important. Among the explanatory variables, the significant predictors of satisfaction with intermediary spaces were "satisfaction with green space" and "satisfaction with condition of facility," which shows they should be emphasized when designing intermediary spaces in mixed-use complexes.

Overall satisfaction with intermediary spaces correlated significantly with satisfaction with complexes, especially with noise, green space, daylight, and condition of facilities. This result emphasizes the need to improve satisfaction with intermediary spaces to achieve higher user satisfaction with mixed-use complexes. The intermediary space may be a small part of a huge complex, and it may be the least interesting space for designers. Because it is a transitional area that connects a mixed-use complex with its surrounding areas and physically 
integrates different functions of the complex buildings and urban spaces, however, the intermediary space should be considered an important part of a mixed-use complex rather than a mere pass-through space barely relevant to the huge building complex. People's positive experience in this space can significantly affect their positive experience of the entire complex.

In conclusion, designers of intermediary spaces need to consider diverse amenity elements to improve user satisfaction levels. Based on the results of this research, intermediary spaces should include the following aspects. First, the amount of green space, number of trees, presence of fountains, and visible adjacent park may increase satisfaction with green space. Second, it is necessary to maintain a distance from noise sources. Third, the program of events and the cleanliness of the space should be recognized as important elements for improving user satisfaction. Fourth, it is necessary to consider proximity to public transportation, as well as information points like maps and signs, to enhance satisfaction.

This study has several limitations, including small sample size, nonrandom sampling, and purposive target complex selection. Thus, the results need to be interpreted carefully, even though data collection followed a rigorous procedure for improving reliability and validity of the research. Still, it was obviously proven that user satisfaction with intermediary spaces and mixed-use spaces are closely related. This research also clearly suggested specific design elements important for improving user satisfaction in intermediary spaces (i.e., noise, green space, daylight, and condition of facilities). In conclusion, intermediary spaces should be regarded not only as transitional areas that link urban spaces to buildings but also as important parts of mixed-use complexes that can affect user satisfaction and experience with the overall building environments.

\section{References}

Allison, T. (1991). Socioeconomic assessment guidance report: Determining the effect of amenity characteristics on business location decisions. Argonne, Illinois: Environmental Assessment and Information Sciences Division of Argonne National Laboratory, 5-7. http://dx.doi.org/10.2172/138729

Beatley, T. (2000). Green urbanism: Learning from European cities (pp. 29-62). Washington, DC: Island Press.

Broadbent, G. (1990). Emerging concepts in urban space design (pp. 183-185). New York, NY: Van Nostrand Reinhold.

Choi, Y. (2008). The characteristics of the mixed-use complex. Review of Architecture and Building Science, 52(7), 48-50.

Coupland, A. (1996). Reclaiming the city: Mixed use development. London, UK: Routledge.

Grant, J. (2002). Mixed-use in theory and practice: Canadian experience with implementing a planning principle. Journal of the American Planning Association, 68(1), 71-84. http://dx.doi.org/10.1080/01944360208977192

Han, G., Park, A., \& Lee, Y. (2009). A study on the function and form of intermediate space in two large mixed-use complexes: New York Rockefeller Center and Boston Prudential Center. Journal of the Urban Design Institute of Korea, 10(2), 57-72.

Helen, W. (1997). Mixed-use development as an agent of sustainability design. In A. Coupland (Ed.), Reclaiming the city: Mixed use development (pp. 149-178). London, UK: E \& FN SPON.

Hirt, S. (2007). The mixed-use trend: Planning attitudes and practices in Northeast Ohio. Journal of Architectural and Planning Research, 24(3), 224-243. http://dx.doi.org/10.1080/09654310500242048

Hoppenbrouwer, E., \& Louw, E. (2005). Mixed-use development: Theory and practice in Amsterdam's Eastern Docklands. European Planning Studies, 13(7), 967-983. http://dx.doi.org/10.1080/09654310500242048

Jang, H., \& Lee, I. (2006). A study on the effect of factors on the use of private-owned pocket parks. Journal of the Urban Design Institute of Korea, 7(4), 47-60.

Jung, Y., Lee, Y., \& Han, G. (2009). A study on agreeability of 'intermediary space' in a large mixed-use complex: Focused on I'Park mall in Yong San. Journal of Architectural Institute of Korea, 25(3), 197-205.

Kim, J., \& Kim, H. (2009). Classification of mixed-use complex development and locational analysis. Proceedings of 2009 National Academic-Industrial Cooperative Conference. Seoul: Korea Planners Association, 161-170.

Kim, K., Chong, W., Kim, D., \& Lee, S. (2008). Feasibility study of multi-level and mixed-use development considering risk factors. Proceedings of 2008 Spring Conference of Korea Planners Association, 285-292.

Kim, S., \& Yang, D. (1997). A study on the users' reaction to urban public space. Journal of the Korea Planners 
Association, 32(1), 53-68.

Kisho, K. (1979). Street and architecture as an intermediary space (pp. 151-156). Seoul, Korea: Talim Cultural Press.

Lau, S., Giridharan, R., \& Ganesan, S. (2003). Policies for implementing multiple intensive land use in Hong Kong. Journal of Housing and Built Environment, 18(4), 365-378. http://dx.doi.org/10.1023/B:JOHO.0000005758.41003.19

Lau, S., Giridharan, R., \& Ganesan, S. (2005). Multiple and intensive land use: Case studies in Hong Kong. Habitat International, 29, 527-546. http://dx.doi.org/10.1016/j.habitatint.2004.04.007

Lee, C., \& Lee, J. (2004). A study on a choice of special functions of the mixed-use development. Journal of the Korea Planners Association, 39(3), 29-40.

Lee, J., \& Kim, J. (2006). A study on the planning of the mixed-use complex based on the urban-architecture system. Journal of Architectural Institute of Korea, 22(11), 261-270.

Lee, H., Park, J., \& Ha, M. (2008). A study on the characteristics of architectural publicity in the mixed-use facilities: Focused on the mixed use facilities in Japan. Journal of Architectural Institute of Korea, 24(6), 181-191.

Lee, K., Moon, J., \& Lee, S. (2008). A study on the characteristics of an intermediate space in mixed-use development: Focused on the pedestrian passage structure. Proceedings of 2008 Spring Conference, Seoul: Urban Design Institute of Korea, 600-608.

Lee, S. (1998). The planning characteristics of mixed-use development. Journal of the Korea Planners Association, 33(5), 63-81.

Lee, S., Lee, S., Kang, B., Kim, S., \& Lee, S. (2002). A study of the analysis of publicity in the inner plaza of complex building: Through examination of user's satisfaction. Journal of Architectural Institute of Korea, 18(6), 61-68.

Lee, Y., \& Yoo, U. (2010). Design strategies of high-rise mixed use complex through a viewpoint of landscape urbanism: Focused on projects of Jerde partnership. Journal of Architectural Institute of Korea, 26(2), 119-128.

Marion, R., \& Lloyd-Jones, T. (1997). Mixed uses and urban design. In A. Coupland (Ed.), Reclaiming the city: Mixed use development (pp. 149-178). London, UK: E \& FN SPON.

Merriam-Webster online dictionary. (2009). http://www.merriam-webster.com/

Moon, H., Chang, S., \& Lee, Y. (2011). A study of user satisfaction in environmental-friendly intermediary space of mixed-use complex. Journal of Architectural Institute of Korea, 27(06), 11-20.

Oh, D. (2006). A study on setting up the concept of city marketing. Journal of the Korea Planners Association, 4l(1), 53-73.

Oxford advanced learner's dictionary. (2009). http://oxfordlearnersdictionaries.com/

Schwanke, D. (2003). Mixed use development handbook (2nd ed.). Washington, DC: Urban Land Institute.

Shin, D., Kim, S., Jeon, Y., \& Choi, Y. (2009). A study on the direction of the legislation of the multi-dimensional mixed-use development for the urban regeneration. Journal of Architectural Institute of Korea, 27(5), 131-138.

Shin, J., \& Kim, H. (2002). The study on the characteristics of the-large scale MXDs: Focus on the publicity of the open space. Journal of Architectural Institute of Korea, 18(5), 27-37.

Strauven, F. (1998). Aldo van Eyck-the shape of relativity. Amsterdam, the Netherlands: Architecture \& Natura.

Trochim, W. (2006). Research methods knowledge base. Retrieved from http://www.socialresearchmethods.net/kb/sampnon.php

Witherspoon, R. (1976). Mixed-use development: New ways of land use. Washington, DC: Urban Land Institute.

Yang, S., \& Lee, H. (2012). An user's satisfaction on publicness of intermediate space on mixed-use complex: Focusing on construction and structure. Journal of Architectural Institute of Korea, 28(1), 207-216.

Zhang, X. Q. (2000). High-rise and high density urban form. In M. Jenks, \& R. Burgess (Eds.), Compact Cities: Sustainable urban forms for developing countries (pp. 245-254). London, UK: Spon Press. 


\section{Copyrights}

Copyright for this article is retained by the author(s), with first publication rights granted to the journal.

This is an open-access article distributed under the terms and conditions of the Creative Commons Attribution license (http://creativecommons.org/licenses/by/3.0/). 